\title{
Farinha de Resíduos de Processamento de Frutas Tropicais: Determinação dos seus Potenciais Antioxidante.
}

\author{
SENA, D. N. ${ }^{1}$; OLIVEIRA, A.F.R. ${ }^{1}$; SOUSA, M.M.A. ${ }^{1}$; ALMEIDA, M. M. B. ${ }^{2}$; SOUSA, \\ P. H. M. ${ }^{3}$ \\ ${ }^{1}$ Aluna de graduação em Engenharia de Alimentos da UFC - Campus do Pici; \\ ${ }^{2}$ Docente da UFC - Campus do Pici, do Departamento de Química Analítica e Físico- \\ Química \\ ${ }^{3}$ Docente da UFC - Campus do Pici, do Instituto de Cultura e Arte. \\ E-mail: deborasnascimento@gmail.com
}

\begin{abstract}
Resumo - Pesquisas envolvendo compostos antioxidantes oriundos de fontes naturais têm sido desenvolvidas em todo o mundo. Assim, objetivo do presente trabalho foi quantificar o total de compostos fenólicos e de carotenoides, assim como avaliar o potencial antioxidante em amostras de farinha de resíduos de goiaba (Psidium guayaba L.), nas variedades vermelha e branca, manga (Mangifera indica L.) caju (Anacardium occidentale L.) e cajá (Spondias mombin L.). Os resíduos foram cedidos por indústrias produtoras de polpa congelada de frutas, estes foram desidratados, triturados e peneirados para obtenção da farinha. A capacidade antioxidante foi determinada total pelo método ABTS, já os polifenóis totais foram determinados utilizando o reagente Folin-Ciocalteau. A determinação dos carotenoides totais foi realizada apartir da extração com $1 \mathrm{~g}$ de amostra em $10 \mathrm{~mL}$ de solução extratora acetona: hexano (4:6). As atividades antioxidantes variaram entre 53,28 $\mu \mathrm{g} / \mathrm{g}$ (goiaba vermelha) e $29,82 \mu \mathrm{g} / \mathrm{g}$ (goiaba branca). As amostras se destacaram por seus altos teores de fenóis totais variando entre $118,25 \mathrm{mg} / 100 \mathrm{~g}$ (goiaba branca) e $638,80 \mathrm{mg} / 100 \mathrm{~g}$ (manga). Tal fato torna as amostras interessantes para a industrialização. Os teores de carotenoides variam entre $0,088 \mathrm{mg} / 100 \mathrm{~g}$ (goiaba vermelha) e $0,292 \mathrm{mg} / 100 \mathrm{~g}$ (cajá), valores inferior aos encontrados na literatura.
\end{abstract}

\section{INTRODUÇÃO}

Pesquisas envolvendo compostos antioxidantes oriundos de fontes naturais têm sido desenvolvidas devido a sua importância na prevenção do desencadeamento das reações oxidativas, tanto nos alimentos como no organismo animal, produzindo os famosos radicais livres (BROINIZI et al, 2007; ROESLER et al, 2007).

Nos últimos anos, uma quantidade substancial de evidências tem indicado o papel chave dos radicais livres e outros oxidantes como grandes responsáveis pelo envelhecimento e pelas doenças degenerativas associadas ao envelhecimento, como câncer, doenças cardiovasculares, catarata, declínio do sistema imune e disfunções cerebrais (SOUSA, 2007). A oxidação é um processo metabólico que leva à produção de energia necessária para as atividades essenciais 
das células. Entretanto, o metabolismo do oxigênio nas células vivas também leva à produção de radicais. Oxidantes são compostos produzidos pelo metabolismo normal do corpo e, se não controlados, podem provocar danos extensivos (ROESLER et al, 2007).

Nos seres vivos, a produção desses radicais é controlada por diversos compostos antioxidantes, os quais podem ter origem endógena, ou serem provenientes da dieta alimentar e outras fontes. Destas últimas destacam-se tocoferóis (vitamina E), ácido ascórbico (vitamina C), polifenóis, selênio e carotenoides. Quando há limitação na disponibilidade de antioxidantes podem ocorrer lesões oxidativas de caráter cumulativo (SOUSA, 2007). De forma geral, denominam-se antioxidantes as substâncias que presentes em concentrações baixas, comparadas ao substrato oxidável, retardam significativamente ou inibem a oxidação do substrato. Os radicais formados a partir de antioxidantes não são reativos para propagar a reação em cadeia, sendo neutralizados por reação com outro radical, formando produtos estáveis ou podem ser reciclados por outro antioxidante (BROINIZI et al, 2007).

O ácido ascórbico tem alta capacidade de ceder elétrons, o que lhe confere um papel essencial como antioxidante no processo de peroxidação lipídica das membranas e lipoproteínas além de ser necessário para a produção e manutenção de colágeno. Já os carotenoides protegem os lipídios dos danos peroxidativos inativando o oxigênio singleto, sem sofrer degradação, através da reação com os radicais peroxila, hidroxila e superóxido (ROESLER et al, 2007; TAVARES et al, 2000).

Assim, objetivo do presente trabalho foi quantificar o total de compostos fenólicos, de ácido ascórbico e de carotenoides, assim como avaliar o potencial antioxidante em amostras de farinha preparada a partir de resíduos proveniente do processamento de goiaba (Psidium guayaba L.), nas variedades vermelha e branca, manga (Mangifera indica L.) caju (Anacardium occidentale L.) e cajá (Spondias mombin L.).

\section{MATERIAIS E MÉTODOS}

Foram coletados resíduos do processamento de goiaba vermelha, goiaba branca, manga caju e cajá, cedidos por indústrias produtoras de polpa congelada de frutas de Fortaleza-CE. $\mathrm{Na}$ indústria, os resíduos das frutas, logo após extração, foram acondicionados em sacos plásticos, armazenados em câmara congelada, posteriormente foram transportados ao Laboratório de Frutas e Hortaliças da Universidade Federal do Ceará onde foram mantidos 
em freezer a $-18^{\circ} \mathrm{C}$. Depois de descongelados a temperatura ambiente foram desidratadas em estufa de circulação forçada de ar a $65^{\circ} \mathrm{C}$ por 60 horas. Após a desidratação foram triturados com auxílio de um processador e peneirados para obter-se a granulometria variando entre $1,0 \mathrm{~mm}$ a $1,4 \mathrm{~mm}$. Os produtos em pó foram armazenados em recipientes envoltos em papel alumínio e filme de PVC a temperatura ambiente.

Para o preparo do extrato utilizado na determinação do potencial antioxidante e polifenóis totais adicionou-se $20 \mathrm{~mL}$ de etanol $50 \%$ a $1 \mathrm{~g}$ da amostra, agitou-se manualmente com bastão de vidro, a mistura permaneceu em repouso, no escuro, por 1h, e centrifugada por 15 minutos a 10.000rpm em centrífuga da marca: Hettich Zentrifugen, modelo: Rotina 380R. Em seguida, o sobrenadante foi recolhido em balão âmbar de $50 \mathrm{~mL}$. Os resíduos que permaneceram no filtro foram re-extraídos, agora utilizando acetona $50 \%$ e o segundo sobrenadante adicionado ao primeiro. Os extratos foram condicionados em frascos âmbar secos sob atmosfera de nitrogênio e armazenados a $-18{ }^{\circ} \mathrm{C}$ até o momento das análises.

A capacidade antioxidante foi determinada pelo método ABTS com algumas modificações. Primeiramente o radical ABTS foi gerado através da reação de $5 \mathrm{~mL}$ de solução aquosa de ABTS $(7 \mathrm{mM})$ e $88 \mathrm{~mL}$ de solução de persulfato de potássio a $140 \mathrm{mM}$ (2,45 mM concentração final). A mistura permaneceu no escuro por $14 \mathrm{~h}$ e em seguida foi diluída com etanol para a obtenção da absorbância de 0,7 $\pm 0,02$ a 734nm usando um espectrofotômetro de marca SHIMADZU, modelo UV-1800. Apos, uma amostra de $30 \mu \mathrm{L}$ do extrato dos resíduos das farinhas das frutas e do antioxidante padrão Trolox (ácido 2carboxilico-6-hidroxi-2, 5, 7,8-tetrametilcromano), tomados como referência, reagiram com 3 $\mathrm{mL}$ da solução resultante do radical ABTS sem incidência de luz. O decréscimo da absorbância a $734 \mathrm{~nm}$ foi medido após 6 min, com o auxílio de uma curva padrão entre 500$1500 \mu \mathrm{M}$ de Trolox. Os resultados foram expressos como $\mu \mathrm{M}$ de capacidade antioxidante equivalente ao Trolox (TEAC) por grama de massa fresca.

Os polifenóis totais foram determinados de acordo com a metodologia descrita por Reynertson et al. (2008), utilizando o reagente Folin-Ciocalteau. As amostras foram analisadas em triplicata e quantificadas através da construção de curva padrão de ácido gálico (0,01 a 0,2 mg de ácido gálico. mL-1) e os resultados foram expressos em mg ácido gálico/g.

A determinação dos carotenoides totais foi realizada a partir da extração com $1 \mathrm{~g}$ de amostra em $10 \mathrm{~mL}$ de solução extratora acetona: hexano (4:6), a solução foi posta em tubo de ensaio e homogeneizada por $1 \mathrm{~min}$. As leituras foram realizadas em espectrofotômetro UV- 
vis (Micronal, Modelo B582) nos comprimentos de onda de 453 nm, 505 nm, 645 nm, 663 $\mathrm{nm}$. O resultado foi expressos em $\mathrm{mg} / 100 \mathrm{~g} \beta$ caroteno.

Os teores de ácido ascórbico foi determinado por meio do método titrimétrico baseado na redução do indicador 2,6-diclorofenolindofenol pelo ácido ascórbico (INSTITUTO ADOLFO LUTZ, 2008), sendo expresso em mg de ácido ascórbico 100 g-1 de amostra.

\section{RESULTADOS E DISCURSÕES}

A Tabela 1 apresenta os valores de atividade antioxidante, fenóis totais e carotenoides para as amostras de farinhas de resíduos de goiaba, das variedades vermelha e branca, caju, manga e cajá.

Tabela 1 - Potencial antioxidantes das farinhas de resíduos de frutas tropicais.

\begin{tabular}{cccc}
\hline \hline Amostra & $\begin{array}{c}\text { At. } \\
\text { Antioxidante }(\boldsymbol{\mu g} / \mathbf{g})\end{array}$ & $\begin{array}{c}\text { Carotenoides } \\
\text { Totais }(\mathbf{m g} / \mathbf{1 0 0 g})\end{array}$ & $\begin{array}{c}\text { Fenois Totais } \\
(\mathbf{m g} / \mathbf{1 0 0 g})\end{array}$ \\
\hline \hline Goiaba Vermelha & 53,28 & 0,09 & 281,9 \\
Goiaba Branca & 29,82 & 0,11 & 118,25 \\
Caja & 32,48 & 0,29 & 390,86 \\
Caju & 36,85 & 0,16 & 212,34 \\
Manga & 38,75 & 0,05 & 638,8 \\
\hline \hline
\end{tabular}

As atividades antioxidantes das farinhas de goiaba vermelha, goiaba branca e cajá foram determinadas pelo método do ABTS e apresentaram valores estatisticamente diferentes (Tabela 1), variando entre 53,28 $\mu \mathrm{g} / \mathrm{g}$ (goiaba vermelha) e $29,82 \mu \mathrm{g} / \mathrm{g}$ (goiaba branca), os valores correspondem à média de triplicatas. Kuskoski et al. (2006), também em estudo de atividade antioxidante em farinha de resíduos de frutas, encontrou valores semelhantes para a farinha de maçã $(24,4 \pm 0,1 \mu \mathrm{g} / \mathrm{g})$ e uva branca $(52,8 \pm 0,1 \mu \mathrm{g} / \mathrm{g})$, porem na análise da farinha de uva vermelha encontrou valores bem menores $(332,6 \pm 0,1 \mu \mathrm{g} / \mathrm{g})$.

As amostras se destacaram por seus altos teores de fenóis totais, o que a torna interessante para a industrialização (VELIOGLU et al., 1998).

Os teores de carotenoides encontrados variam entre $0,09 \mathrm{mg} / 100 \mathrm{~g}$ (Goiaba Vermelha) e 0,29mg/100g (cajá), valores inferiores ao relatado superóxido Lima (2002) que fez análise da polpa do pequi in natura. No entanto, o teor reduzido de carotenoides se deve ao fato que os resíduos de frutas foram transformados em farinha para posteriores análises. 
Consequentemente, os carotenoides estarão presentes em quantidades maiores na polpa in natura do que na raspa desidratada.

\section{Conclusão}

As amostras estudadas apresentam consideráveis teores de fenóis e carotenoides totais, fato este que faz destes produtos uma fonte promissora de compostos antioxidantes cuja produção e incorporação na dieta alimentar de humanos deveria ser estimulado.

\section{Referências}

BROINIZI, P.R.B.; ANDRADE-WARTHA, E.R.S.; SILVA, A.M.O.; NOVOA, A.J.V.; TORRES, R.P.; AZEREDO, H.M.C.; ALVES, R.E. MANCINI-FILHO,J. Avaliação da atividade antioxidante dos compostos fenólicos naturalmente presentes em subprodutos do pseudofruto de caju (Anacardium occidentale L.). Ciências e Tecnologia Alimentos, Campinas, n. 27, v. 4, p. 902-908, 2007.

INSTITUTO ADOLFO LUTZ. Métodos físico-químicos para análise de alimentos. Coordenadores: Odair Zenebon, Neus Sadocco Pascuet e Paulo Tiglea, $4^{\text {a }}$ Ed., São Paulo: Instituto Adolfo Lutz, 2008. p. 1020.

KUSKOSKI, E. M.; ASUERO, A. G.; ORALES, M. T.; FETT, R. Frutas tropicais silvestres e polpas congeladas: atividade antioxidante, polifenóis e antocianinas. Ciência Rural, v. 36, n. 4, p.1283-1287, 2006.

LIMA, V.L.A.G.; MÈLO, A.E.;LIMA, D.E.S. Fenólicos e Carotenoides Totais em Pitanga. Scientia Agricola, v.59, n.3, p.447-450, jul./set. 2002

ROESLER,R.; MALTA,L.G.; CARRASCO,L.C.; OLANDA,R.B.; SOUSA,C.A.; PASTOR,G.M. Atividade antioxidante de frutas do cerrado. Ciências e Tecnologia Alimentos, Campinas, n. 27, v. 1, p. 53-60, 2007.

RE, R.; PELlEGRINI, N.; PROTEGGENTE, A.; PANNALA, A.; YANG, M.; RICEEVANS, C. Antioxidant Activity Applying An Improved ABTS Radical Cation Decolorization Assay. Free Radical Biology \& Medicine, v. 26, n. 9-10, p. 1231-1237, 1999.

REYNERTSON, K. A.; YANG, H.; JIANG, B.; BASILE, M. J.; KENNELLY, E. J. Quantitative analysis of antiradical phenolic constituents from fourteen edible Myrtaceae fruits. Food Chemistry,London, v. 109, n. 4, p. 883-890, 2008.

SANT'ANNA, M.E.B.; MIRANDA, M.S. Avaliação microbiológica das etapas de produção da farinha de mandioca no Recôncavo Baiano. Magistra, Cruz das Almas, v. 16, n. 1, p. 25 $32,2004$. 
SOUSA,C.M.M.; SILVA, H.R.; VIEIRA-JR.,G.M.; AYRES,M.C.C.; COSTA, C.L.S.; ARAÚJO,D.S.; CAVALCANTE,L.C.D.; BARROS,E.D.S.; ARAÚJO, P.B.M.; BRANDÃO,M.S.; CHAVES,M.H. Fenóis Totais E Atividade Antioxidante De Cinco Plantas Medicinais. Química Nova, v. 30, n. 2, p. 351-355, 2007.

TAVARES, J. T. Q.; SILVA, C. L.; CARVALHO, L. A.; SILVA, M. A.; SANTOS, C. M. G. Estabilidade Do Ácido Ascórbico Em Suco De Laranja Submetido A Diferentes Tratamentos. Magistra, Cruz das Almas-BA, v. 12, n. 1/2, jan./dez., 2000.

VELIOGLU, Y.S.; MAZZA, G.; GAO, L.; OOMAH, B.D. Antioxidant activity and total phenolics in selected fruits, vegetables, and grain products. Journal of Agricultural and Food Chemistry, v.46, p.4113-4117, 1998. 